Discrimination, Vulnerability, and Justice in the Face of Risk

Theresa A. Satterfield, C.K. Mertz, and Paul Slovic

Decision Research

1201 Oak Street

Eugene, Oregon 97401

Abbreviated title: Vulnerability, Justice, and Risk

Submitted to Risk Analysis following conditional acceptance

May, 2003

Direct correspondence to: Theresa A. Satterfield

Decision Research

1201 Oak Street

Eugene, Oregon 97401

This study was supported by a grant to Decision Research from the National Science Foundation (Grant No. SES-9876581) 
Abstract: Vulnerability, Discrimination, and Justice in the Face of Risk

Recent research finds that perceived risk is closely associated with race and gender. In surveys of the American public a subset of white males stand out for their uniformly low perceptions of environmental health risks, while most nonwhite and nonmale respondents reveal higher perceived risk. Such findings have been attributed to the advantageous position of white males in American social life. This paper explores the linked possibility that this demographic pattern is driven not simply by the social advantages or disadvantages embodied in race or gender, but by the subjective experience of vulnerability and by sociopolitical evaluations pertaining to environmental injustice. Indices of environmental (in)justice and social vulnerability were developed as part of a U. S. National Risk Survey $(n=1,192)$ in order to examine their effect on perceived risk. It was found that those who regarded themselves as vulnerable and supported belief statements consistent with the environmental justice thesis offered higher risk ratings across a range of hazards. Multivariate analysis indicates that our measures of vulnerability and environmental [in]justice predict perceived risk but do not account for all of the effects of race and gender. The paper closes with a discussion of the implications of these findings for further work on vulnerability and risk, risk communication, and risk-management practices generally.

Keywords: perceived risk, environmental justice, vulnerability, race, gender 


\subsection{INTRODUCTION}

This paper examines the American public's ideas about discrimination, vulnerability, and [in]justice as they pertain to African-American, Hispanic, Asian, and Anglo-American perspectives on health and environmental risks. It is rooted in studies of perceived health and environmental risks, ${ }^{(1-3)}$ but extends that work by recognizing the possible influence on perceptions of risk of (a) beliefs closely affiliated with the environmental justice thesis and (b) the subjective experience of discrimination, and economic and physical vulnerability.

Considerable attention has been granted of late to the relationship between gender, race, environmental values and environmental risks. Gender differences regarding the values, beliefs, and attitudes affiliated with pro-environmental positions have been found in multiple studies. ${ }^{(4-6)}$ Kalof et al. ${ }^{(7)}$ recently found significant differences in pro-environmental beliefs between whites (less pro) and Hispanics (more pro), and white males (less pro) and white females (more pro).

Studies of the effects of gender on perceived health and environmental risks have found that women are more risk averse than men. ${ }^{(6,8)}$ A 1994 study by Flynn and colleagues ${ }^{(1)}$ found a 'white male effect' wherein nonwhite Americans tended to report higher risk perceptions than did whites. The authors further discovered that it is a subset of white males who tend to be different from everyone else in terms of their perceptions of risk. Across a set of 25 environmental health-risk items, white males consistently saw less risk than nonwhites (males and females) and white females. The perceptions of risk held by white females were very similar to those of nonwhites. Survey evidence from the Detroit metropolitan area reported by Mohai and Bryant ${ }^{(9)}$ also indicated that African-Americans were more concerned than Whites about environmental risks, particularly in reference to the health and safety effects of pollution, and the environmental conditions of one's community. Jones ${ }^{(10)}$ similarly found greater concern, among 
African Americans, for risks attributed to nuclear power and toxins. These demographic differences have been upheld in examinations of specific risk domains. For example, a recent study of outdoor air pollution found that differences in perceived risks were greatest for white men and nonwhite women and that differences between men and women were less frequent than between whites and nonwhites. ${ }^{(11)}$

Race and gender differences in reference to perceived risk have been attributed to the reduced social and formal decision making power held by women and minorities as compared to White men; ${ }^{(8)}$ to women's greater role as caregivers; ${ }^{(5)}$ to the greater likelihood of exposure to environmental harm facing members of minority groups; ${ }^{(9)}$ and to income, education, and political orientation. ${ }^{(1)}$ Interestingly, however, little work has been done on the relationship between support for the environmental justice thesis and risk perception or the relationship between perceived vulnerability and perceived risk.

The environmental [in]justice thesis is that minority populations are disproportionately burdened by the health and community compromising bi-products of industrialization. Early studies by the $\mathrm{NAACP}^{(12)}$ and Bullard ${ }^{(13)}$ found that technological hazards are more apt to be located in and less likely to be properly remediated in minority communities. Subsequently, the thesis has been extensively tested and refined as concerns the distribution of different contaminants, ${ }^{(14-16)}$ hazardous wastes, and the siting of noxious facilities, demonstrating the specific circumstances under which inequitable distribution, treatment, and compensatory actions are evident. ${ }^{(17-20)}$ It is reasonable to assume that significant support for the environmental justice thesis will be found across survey respondents, given the burgeoning of the environmental justice movement and the accompanying [and trenchant] mobilizing claims which assert that law and regulation need address widespread inequities in the distribution of environmental health 
risks. ${ }^{(21-22)}$ Further, belief statements that support or reject these justice propositions are easily tested and can, in turn, be examined in reference to perceived risk.

Vulnerability to risk has been studied by geographers who are principally concerned with the political economy within which a community is nested and hence its vulnerability to famine, hunger or natural hazards and/or that community's ability to recover from such shocks, crises, or stressors. ${ }^{(23)}$ But only very few risk papers have posited substantive links between perceived vulnerability and perceived risk. In a review of the literature on gender and risk, Bord and $\mathrm{O}^{\prime}$ Connor ${ }^{(5)}$ reference several studies which find that "women consistently exhibit much stronger perceptions of vulnerability to illness and physical debilitation" (p. 832). The authors interpret white women's high risk perceptions as an artifact of perceived vulnerability. A study by Kraus and colleagues ${ }^{(24)}$ of toxicological knowledge and risk perceptions designated perceptions of vulnerability "as a key factor mediating [toxicologists'] attitudes toward public fear of [chemicals]" (p.226). Toxicologists who believe that humans are less vulnerable (than are animals) to the adverse effects of chemicals and who also disagree with the reliability of animal studies (i.e., see them as poor indicators of human response), believe that people are unnecessarily alarmed by small amounts of pesticides.

Vulnerability is covertly defined in these above studies as a generalized feeling of enhanced susceptibility to harm. The idea is akin to early social-psychological studies of discrimination which emphasized the action-paralyzing effects of discrimination. ${ }^{(10)}$ It is thus plausible to consider discrimination as a dimension of vulnerability but a fuller definition of vulnerability should recognize that vulnerability can be expressed across multiple dimensions. The operational definition of vulnerability developed herein thus includes ideas about perceived personal fragility, perceived economic insecurity, and/or physical vulnerability (e.g., such as that 
affiliated with poor health or health care).

\subsection{Research Questions}

Concern with demographic as well as justice- and vulnerability-driven responses to risk raises four core research questions to which this paper turns. First, and fundamentally, is the 'concern gap' posited by Mohai and Bryant ${ }^{(9)}$ and Jones ${ }^{(10)}$ or the 'white male effect' found by Flynn et al. ${ }^{(1)}$ upheld by a representative national sample and by over-sampling in minority communities to ensure a robust representation of African American and Hispanic populations? Specifically, are white males less concerned about health and environmental safety problems, particularly those attributed to toxins, nuclear hazards, coal and oil facilities, as compared to all other groups (nonwhite men, white and nonwhite women)? Second, to what extent does an experience of discrimination, and vulnerability more broadly, drive that concern/effect? Third, to what extent do beliefs about environmental justice and/or a stated sociopolitical awareness of environmental injustices also explain the perception of risk? Fourth, are white and nonwhite differences in perceived risk erased or significantly reduced when expressions of vulnerability and injustice are accounted for? And, are these new variables more important than education or income?

\subsection{METHODS}

The data presented herein were collected as part of a national telephone survey designed to examine topics ranging from perceived risks, worldviews, trust, environmental values, discrimination, vulnerability, and justice. These question sets are detailed more fully in the appropriate results sections. The survey design included an oversampling of nonwhite groups to provide a more reliable and robust dataset from which to allow further examination of the relationship between risk, race, and gender. Only those portions of the survey data relevant to 
this paper are discussed.

\subsection{Administration of the Survey}

A stratified random sample of household members over 18 years of age in the U.S. was surveyed by telephone from September 27, 1997 through February 3, 1998. The objective w as to obtain a general population sample plus three oversamples of Hispanic, African-American, and Asian census tracts. Random digit dialing was used. All American households, with telephones, had an equal chance of being selected. For the oversamples, numbers were randomly generated using telephone exchanges in census tracts with incidents of over $75 \%$ of the Asian population and over $80 \%$ for the Hispanic and Black populations. This oversample covered $12.7 \%$ of the Hispanic population, $12.6 \%$ of the Black population, and $14.0 \%$ of the Asian population of the U.S. For the Asian group, additional pieces of sample were added from Genesys Sampling System, Inc. The Genesys sample was randomly generated by last name from all American telephone exchanges and had a purported incidence of $90 \%$.

A total of 1204 completed interviews were obtained, for an overall response rate of $46.8 \%$. The response rates ranged from $32.6 \%$ for the Asian oversample to $54.4 \%$ for the Hispanic oversample. The mean age was 43.5 with $45.0 \%$ males and $55.5 \%$ females. The average interview length was approximately 35 minutes. Interviewing resulted in a sample of 672 white-Caucasians, 180 Hispanics, 217 African Americans, 101 Asians, 22 American Indian and multi-racial persons, and 12 who defined themselves as "other". As the demographic characteristics of the 12 others were unknown, they were omitted from our analyses, resulting in a sample of 1192 . When necessary for the analysis, the African American, Hispanic, Asian, American Indian and multi-racial groups were collapsed as an aggregate 'nonwhite' male or female group. This resulted in 289 white males, 383 white females, 245 nonwhite males and 275 
nonwhite females. However, when generalizing to the U.S. population as a whole, weighting is necessary due to the oversampling of nonwhites. The general and oversamples were weighted to the 1997 U.S. population as a whole in terms of race and gender, resulting in a weighted sample of 861 respondents.

\subsection{RESULTS}

\subsection{Risk Ratings - Demographically Defined}

Studies of perceived risk have shown that the qualities of a hazard or risk object strongly influence the perception of risk. In particular, it has been established that risks the public views as dreaded, likely to be fatal, involuntarily or unfairly imposed, beyond any one individual's control, or generated by mistrusted institutions, tend to evoke strong risk-averse responses. ${ }^{(2,25-26)}$

In this study, respondents rated 19 different sources of risk. Most of the risk items are the product of technological hazards (e.g., pesticides, coal and oil burning plants, stored nuclear waste, lead in paint or dust); a few items are affiliated with health-risky behaviors (multiple sex partners, street drugs); others are the product of natural phenomena (asteroids, natural disasters); a few final risk items are specific to consumer goods (motor vehicles, cellular phones). Respondents were asked to rate each risk-object as posing almost no risk, a slight risk, a moderate risk, or a high risk to the American public. ${ }^{1}$ These response categories were coded 1 to 4, respectively. An overall risk perception index was created by computing an average score across the 19 individual risk items for each respondent. The Cronbach alpha for this index is .90 , which indicates high reliability.

Mean risk ratings by race, ethnicity (for Hispanic respondents) and gender are represented in Figure $1 .{ }^{2}$ The highest mean risk scores were assigned by respondents to "street 
drugs" and "multiple sexual partners." The lowest risk scores were assigned to vaccines, cellular phones, and asteroids.

In Figure 1, all male and female respondents identifying themselves as AfricanAmerican, Hispanic, Asian, Native American, or multiracial are represented respectively as nonwhite males and nonwhite females. The figure shows that white males offer uniformly lower risk ratings as compared to the ratings offered by nonwhite females, nonwhite males, and white females. This pattern is consistent across 18 of the 19 possible hazards. There existed two deviations from this general pattern. First, for "motor vehicles" nonwhite and white males offer similar and slightly lower risk ratings as compared to those offered by white and nonwhite females. Second, nonwhite females offer higher risk ratings than do most other groups. Using a tukey post-hoc significance test, the risk ratings of nonwhite females are higher than (and significantly different from) those offered by white males on all 19 items; they differ significantly from white females on 11 risk items and from nonwhite males on 10 items. ${ }^{3}$ In this sense, 'white males' are not the only 'atypical' group as to a lesser degree nonwhite females exhibit an atypical pattern

It is admittedly reductionist to categorize African-American, Hispanic, Asian, Native American, and multiracial men and women as, simply, nonwhite [males and females]. However, for our purposes here, a fuller accounting of race- and gender-specific responses indicates no consistent pattern of between group differences that are race or race-and-gender specific. No single (male or female) or combined (male and female) group of African-American, Hispanic, or Asian respondents emerge as consistently and comparatively risk averse or risk tolerant. When comparing, however, within group differences between men and women (African-American men as compared to African-American women, etc.), women in the respective nonwhite groups are 
somewhat more likely to provide higher risk ratings. African-American and Hispanic females' mean risk ratings are higher than those offered by corresponding males on 13 of 19 rated hazards. An exception is the group of Asian women who provided higher ratings on only 5 of the 19 posed risks.

These findings confirm earlier results summarized as the "white male effect" which found that white men have substantially lower mean responses to hazards than do any other male or female group. ${ }^{(27,1)}$ As with these earlier studies ${ }^{(27,1)}$ we too found that a subset of white males offered the lowest risk ratings. They tended, in turn, to drive down the overall risk ratings for white men. This subset of white males was arrived at by starting with the lowest-scoring white male on the risk perception index and moving up the distribution, adding white males until the mean score on the index for the remaining white males matched the mean score for all other persons (all females and all nonwhite males) in the sample. This resulted in $48 \%$ of the white males in the sample remaining in the low-risk perception white male subgroup. This subset of white men were found to perceive the benefits from science, technology and industry as outweighing the risks and to be disinclined toward citizen-driven decision making (i.e., they were more authoritarian than egalitarian in outlook). They were also more likely to have accessed higher levels of education, to be politically conservative, and/or to have higher average incomes than did other respondents. ${ }^{4}$ Using the same dataset recorded here, Finucane et al. ${ }^{(27)}$ found equally that white males were more likely to be individualistic and fatalistic (versus egalitarian) in worldview and were less likely than all others to be bothered by the stigmatizing effects of risk events (e.g., the stigmatizing of properties or businesses because of their proximity to transportation routes used for the shipping of nuclear wastes to storage sites). ${ }^{5}$ 
The "white male effect," confirmed herein with a broader sampling and over-sampling of minority populations, thus counters the common misperception that minority groups, in particular African-Americans, are unconcerned about the environment. ${ }^{(28)}$ Specifically, this white male effect is most clearly upheld when considering cross-group perceptions of health and environmental hazards, particularly toxins and nuclear hazards, as was predicted by Mohai and Bryant $^{(9)}$ and Jones. ${ }^{(10)}$

\subsection{Risk as a sociopolitical expression}

3.2.1 Discrimination and vulnerability. If we begin with the knowledge that (a) the perceptions of health and environmental risks held by African-Americans are similar to most other nonwhite male and all female groups, and (b) that a substantial percentage of white males see the world as much less risky than does everyone else, then some effort must be taken to explain these differences. Flynn et al. ${ }^{(1)}$ found that when they controlled for such demographic variables, age, education, and income as well as variables such as perceived importance of technology, gender and race remained highly significant predictors of the risk. This led them to conclude that sociopolitical (not demographic) variables likely explained the influence of gender and race on risk perceptions. White males, they surmised, may see less risk in the world because they in fact create, manage, control, and benefit from the major technologies and activities affiliated with many of the above environmental risks. Women and nonwhite men might see the world as more dangerous because in many cases they have less power and control over what happens in their communities and their lives. As noted earlier, Bord and $\mathrm{O}^{\prime}$ Connor ${ }^{(5)}$ interpret white women's high risk perceptions as an artifact of perceived vulnerability.

To examine in greater detail the vulnerability and sociopolitical underpinnings of this race and gender effect on perceived risk, we first looked at the relationship between respondents' 
risk ratings and their subjective expressions of discrimination and vulnerability. Self-reports of discrimination as well as multiple expressions of vulnerability were operationalized using a sixitem question set. ${ }^{6}$ These survey items are as follows:

- I often feel discriminated against.

- My whole world feels like it's falling apart.

- People like me aren't benefiting from the growth of the economy.

- I have very little control over risks to my health.

- Would you rate your personal health as excellent, good, fair, or poor?

- How would you rate the quality of medical care that is available to you?

Together these items identify respondents who, regardless of race, "feel discriminated against." More broadly, the question set identifies those who feel they have poor control over their lives, feel they do not benefit from economic opportunities or medical services available to other persons. The response-frequency distributions for the six vulnerability questions are represented in Table I.

We expected and did find that white respondents, male and female, differed considerably from nonwhite respondents in their agreement with the discrimination/vulnerability items. A comparison across respondent groups reveals that the vast majority of white males $(81.3 \%)$ and females (78.3\%) do not "feel discriminated against" whereas about one-half of nonwhite men (49.4\%) and women (50.6\%) report frequent ("often") feelings of discrimination. A small majority of nonwhite females $(54.6 \%)$ report that "people like me aren't benefiting from the economy" whereas only a small minority of white males (29.4\%) agree with the same statement. White females and nonwhite males fall somewhere in between at $41.3 \%$ and $43.7 \%$ disagreement respectively. The majority of respondents disagree with or rate as good/excellent the other index 
items (about the world falling apart and health status), although the percent disagreement is higher for white men than for all other respondent groups on the health status question.

A social vulnerability score for each respondent was created by calculating the mean score across the six items. Items were scored so that a high score on this index indicated high social vulnerability. Individual item responses were coded 1 (strongly disagree/excellent) to 4 (strongly agree/poor). The scale reliability was examined by calculating the Cronbach alpha for the six items, which was .65. Although the coefficient alpha is lower than desirable, a factor analysis found all six items loaded on one factor, thus, we felt the index adequate to proceed with analyses. ${ }^{(30)}$ Comparison of the aggregate mean scores for the vulnerability index as a whole is instructive. At the low end, white males' mean vulnerability score is 1.96; at the high end, nonwhite females' score is 2.30 . The difference between white males and all other groups is significant as is the difference between white females and all other groups. [The implications of these indices for risk scores are elaborated in section 3.2 .4 below.]

\subsection{Discrimination and risk. One item - "I often feel discriminated against" - is} particularly instructive. The pattern of response is representative of the other vulnerability items. Mean scores for the 19 risk items were compared to respondents who agreed versus disagreed with this 'discrimination' statement. Figure 2 indicates that those who agree with the statement "I often feel discriminated against" rate the risks posed by all 19 hazards as higher than do those who disagreed. Moreover, the largest differentiations in risk scores were specific to environmental health hazards: stored nuclear waste, chemical manufacturing, lead in paint and dust, coal/oil burning plants, radon in homes, and electromagnetic fields. Stored nuclear waste is the technological hazard most dreaded in many risk studies. ${ }^{(2)}$ The presence of lead has been linked to developmental disabilities in children. ${ }^{(31-33)}$ Lead in dust and plumbing infrastructure is 
also prevalent in the physically decaying urban neighborhoods, some of which house a disproportionately large number of poor and minority populations. Differences in perceived risk were not, however, pronounced for acts of God (natural disasters with the exception of asteroids). Differences were also minimal for risk items that are extremely familiar (motor vehicles) and for those risks over which individuals have personal control (multiple sexual partners, second-hand smoke).

3.2.3. Environmental justice and risk. Vulnerability and discrimination are characterized by the above index items as (largely) subjective expressions. ${ }^{7}$ This is logical to the extent that people living in contaminated African-American communities have linked the experience of toxic exposure to the experience of discrimination. ${ }^{(34)}$ But it is also the case that judgments about risk develop with substantial reference to one's social, and not solely subjective, context. Increasingly, in minority communities attentive to environmental concerns, that social context is characterized by the framing of hazards and toxins as risks that are unjustly imposed on minority communities. That is, many risk problems are framed by minorities as questions of justice and fairness and not as technical, scientific or economic problems per se (Ref. 35, p. 172). Further, several authors have aptly identified the environmental justice movement as a master ideological frame whereby activists are compellingly mobilized to make "causal attributions or develop vocabularies of motive" that interpret toxic exposure as a persistent expression of societal racism (Ref. 22, pp. 514-515). ${ }^{(36)}$

For these reasons, the language of environmental justice offered a viable source for developing survey questions that captured socially-oriented explanations or judgments about the equity of risk distributions in public life. We therefore developed a question set that sought to identify respondents who support the environmental justice hypothesis and believe that 
hazardous facilities ought not be sited in minority communities. These environmental-justice items are as follows:

- I think hazardous facilities are more common in minority communities.

- For economic reasons, minority communities are forced to accept more industrial pollution than non-minority communities.

- Minority communities lack the political clout to stop hazardous facilities from being located near them.

- The government should restrict the placing of hazardous facilities in minority communities.

Table II discloses the frequency distributions for the question items across the four raceand gender-specified respondent groups. Once again there is considerable variation between the judgments offered by white males as compared to nonwhite male and female respondents. On the first three questions, the opinion of white men is relatively close to that of white women; the point spread between these two groups does not exceed five percentage points on any of these three items. On the fourth question, slightly more white women $(71.8 \%)$ than white men $(63.7 \%)$ agree that "the government should restrict the placing of hazardous facilities in minority communities." Conversely, the response variation for white males as compared to nonwhite females is substantial. Approximately $19 \%-20 \%$ more nonwhite females and nonwhite males agree that "minority communities lack the political clout to stop hazardous facilities from being located near them," as compared to white males and females. Similarly, as many as $27.2 \%$ more nonwhite women and $17 \%$ more nonwhite men agree that "the government should restrict the siting of hazardous facilities in minority communities" as compared to white males. Also noteworthy is the finding that nonwhite males and nonwhite females do not hold divergent views 
about environmental justice. The mean index scores (based on a four-point agree/disagree scale) are also listed at the bottom of Table II.

An environmental justice score for each respondent was created by computing the mean score across the four items. The items are scored so that a higher score indicates greater perceived environmental injustice. The index is internally consistent as indicated by the Cronbach alpha for the four items, which was .79. The scores in Table II indicate that only .08 points separate nonwhite men and women; conversely, a .30 point difference in mean scores separate the opinion of white and nonwhite men and .38 points between white men and nonwhite women.

As with the discrimination statement in the vulnerability index, one item in the environmental justice index emerges as particularly instructive with regard to risk ratings. Figure 3 shows that those who disagreed with the statement, "The government should restrict the placing of hazardous facilities in minority communities," have consistently lower risk ratings than do those who agree with the statement. Figure 3 indicates that differences in mean risk scores are greatest for stored nuclear waste, pesticides, nuclear power plants, tap water, and for reasons that are not clear, cellular phones.

3.2.4. Justice and vulnerability as it applies to risk. The implications for perceived risk of the combined findings on the vulnerability and environmental justice indices can be examined by comparing "high" and "low" responses on both indices to respondents' risk ratings. This comparison was accomplished by separating the distributions for each of the two indices into approximately equal size high, medium, and low groups. Those identified as "high" on the vulnerability index had a mean score of at least 2.3 points; whereas the mean score for low respondents in the vulnerability group did not exceed 1.8 points. Respondents in the high 
environmental justice group scored 3.0 points or higher; whereas respondents in the low group scored a maximum of 2.5 points. Respondents who were "high" on both indices were combined to create a "high justice/high vulnerability sub-group" (weighted, $n=129$ ). Similarly, respondents who were low on both indices were combined to create a "low vulnerability/low justice" subgroup (weighted, $n=161$ ). These graphed results are displayed in Figure 4 .

The consistently lower risk ratings offered by respondents in the low as compared to high justice/vulnerability group suggests that, combined, justice and vulnerability are powerful predictors of risk. For no hazard item do respondents in the respective vulnerability-justice groups offer similar risk ratings. Rather, the difference across groups is substantial for all but two risk items - risks posed by motor vehicles and the risk of multiple sexual partners, both of which are voluntary risks and whose consequences are relatively familiar. The mean differences between the two groups for all other hazard items exceed .37 and are statistically significant. More importantly, the difference on 13 of 19 items is .60 or greater, with differentiation greatest (.69 and higher) for the items stored nuclear waste, nuclear power plants, chemical manufacturing, coal/oil burning plants, lead in dust or paint, and radon in homes. ${ }^{8}$

\subsection{Justice, Vulnerability and the White Male Effect}

3.3.1. Reexamining "The white male effect." Given the strength of the above indices as they apply to risk, it is appropriate to reexamine the stability of the "white male effect" when that effect is further qualified by judgments of vulnerability and justice. That is, what happens to the "white male effect" when high environmental justice and vulnerability scores are accounted for? In the comparative risk ratings first reported above in Figure 1, the risk responses recorded for white males were consistently and significantly lower than were responses by all of the female and male nonwhite respondents. Plotted, this produced the discrete "white male" line on the 
graph's left-hand side. This effect is, however, substantially altered when risk ratings are examined for only those respondents recorded as having combined high vulnerability and environmental injustice scores. The sample sizes for this combined high vulnerability/injustice group are relatively small, thus the results can only be regarded as suggestive (white male, $n=$ 34; white female, $n=40$; nonwhite male, $n=53$; nonwhite female, $n=95$ ). ${ }^{9}$ Further, there are considerably more nonwhite females in this group. A full one-third (34.5\%) of nonwhite female respondents fall in the high vulnerability/high justice group as compared to $11.8 \%$ of white males. Figure 5 plots the risk ratings for these high vulnerability/injustice subsamples.

The results recorded in Figure 5 indicate that white males who scored high on both the vulnerability and environmental injustice indices are no longer a group with risk perceptions markedly different from all other females and all nonwhite males. This is evidenced by the intermingling of the line representing the plotted white male ratings with the lines representing all other groups. That is, much of the race and gender effect previously documented in Figure 1 is eroded when social vulnerability and environmental justice are accounted for in this way.

3.3.2. Regression analysis of the white male effect. Further testing to determine whether the "white male effect" is a vulnerability and justice effect or a demographic effect (i.e., driven primarily by race or gender) can be accomplished by using a regression model to predict risk responses based on race and gender only (Model 1), and thereafter, by expanding the model to see whether our measures of social vulnerability and environmental justice can account for the race-gender effect. The results of this two-step analysis are recorded in Table III below.

Model 1, which attends only to race and gender, was highly significant $[F(2,1189)=$ 87.03, $p<.0001]$ as can be seen in Table III. The standardized coefficients for both gender and race $(.28$ and -.22 , respectively) were significant as well with women and nonwhites exhibiting 
higher perceptions of risk. This effect was, however, somewhat diminished when controlling for vulnerability and environmental justice as demonstrated by the results from the Model 2 analysis. Race and gender were still significant predictors of risk perception, but the standardized coefficient for race was lower (-.10) in Model 2. The coefficient for gender (.24) was slightly diminished after controlling for these new factors.

When combined, vulnerability and environmental justice explained 16.68 percent of the variance in risk perception. When race and gender are added to the model, $23.46 \%$ of the variance is explained, an increase of $6.8 \%$. To test whether race and gender still contributed independently to the prediction of risk perception, an R-squared test of the change in proportion of variance explained was performed. The results found that the explanatory power of gender and race remain significant though somewhat diminished. Gender provided a $5.81 \%$ increase in $R$-squared, the largest effect over and above the variables of environmental justice and vulnerability, as compared to race, which garnered an R-squared increase of just under $1 \%$. The respective $F$ values for the change in R-squared were $F(3,1,180)=88.49, p<.0001$ and $F(1$, $1,179)=14.85, p<.001$. Thus, while vulnerability and beliefs about environmental injustice are important predictors of risk perception, they do not completely explain or account for the effect of race and gender. Gender, in particular, remains robust in its own right. Race retains a smaller, but still significant influence on perceptions of health risks. In sum, all four variables are important independent predictors of risk perception, with social vulnerability and gender being the strongest predictors followed by environmental injustice and then race.

Additional regression analyses were conducted to determine whether the white male effect could be accounted for by factors such as age, education, income, political orientation (liberal vs. conservative) and religious commitment (church attendance). It could not. The 
coefficient for vulnerability (.20) was somewhat lower after controlling for these other variables. However, education emerges as a significant predictor of risk, a finding already noted by others (e.g., Ref. 27). Gender and race remained strong predictors of risk perception, even after all of the above variables were entered into the regression equation (see Table IV).

\subsection{DISCUSSION}

Four important results have emerged from this study. First, these results replicate the "white male effect" which found that across the American population, white males rate the risks that hazards pose as lower than most other demographic groups. ${ }^{10}$ In addition, nonwhite females provide higher risk ratings than all others; thus white males cannot be characterized accurately as 'the only atypical group.' These results also uphold the supposition of Mohai and Bryant ${ }^{(9)}$ and Jones $^{(10)}$ that African-Americans in the United States are more rather than less concerned about environmental risks, particularly when those risks concern the health and safety effects of pollution. Second, strong (affirmative) feelings of discrimination and vulnerability and evaluative judgments of justice, as well as strong support for environmental injustice claims are closely linked to high perceptions of environmental health risks. This suggests in turn that both subjective experiences of vulnerability and evaluative judgments of [in]justice are central to the perception of risk. Third, white males with high perceptions of vulnerability and environmental justice tend to rate risks in a manner that is similar to all other groups (white females, and nonwhite males and females). Fourth, vulnerability, gender, environmental justice, and race (in order of strength) are significant predictors of health and environmental risk perceptions. Gender remains a robust predictor of risk as does - to a lesser extent - race, but the influence of these two demographic variables (particularly race) is explained in part by our measures of vulnerability and environmental injustice. 
It should be emphasized that these are preliminary results to the extent that (a) the subsamples from all groups whose high vulnerability/high injustice perspective diminished the original white male effect were relatively small, and (b) the indices we developed for measuring vulnerability and environmental injustice represent first attempts and as such may have insufficiently characterized these constructs. Regression analysis confirms that our measures are only partially, at best, responsible for the race and gender effect on perceived risk. Gender, as a particularly robust predictor of risk, is still relatively unexplained. Thus, expanding both indices to better accommodate explanations for the gender effect might well be productive. Upon reviewing the literature on gender and risk, Davidson and Freudenburg ${ }^{(6)}$ have argued that the best explanation for differences in risk perception between white men and women is the hypothesis that the risks posed by health and safety problems are more salient to women due to their socially prescribed roles as nurturers and care providers. This provides a viable starting point, particularly as concerns the vulnerability index. But the nurturer hypothesis does not explain the perceptions of nonwhite men, perceptions that were found herein to be somewhat similar to those held by white and nonwhite women. It is possible that while some insights have been achieved here and elsewhere as to the subjective and sociopolitical perspectives of risk perceivers, we do not as yet fully understand precisely what different risks mean to different perceivers. Gustafson has convincingly argued that "what appears ... in a questionnaire to be one and the same risk may not always mean the same thing to women and men" (Ref. 37, p. 807). His analogous case is that men and women alike fear or see violent crime as risky. Yet, investigations of meaning reveal that men read physical violence into the term 'violent crime', whilst women primarily fear rape and other forms of sexual assault and thus read this latter meaning into the term 'violent crime.' 
Improved indices aside, our findings have implications for risk communication and risk remediation practices. That is, procedures employed by regulatory agents to both communicate about risk and physically manage the hazards that demand remediation attention (e.g., many Superfund sites) could benefit from greater sensitivity to cross-group perspectives on the perceived relationship between risk, vulnerability, and justice. If, for instance, high risk ratings are a product of subjective states of vulnerability, such states could reasonably be expected to influence the uptake and response to risk messages. Such messages may be met with resistance, denial, anxiety, or misinterpretation due to one's heightened perception of susceptibility to possible consequences. In a different vein, and in reference to justice, Vaughn has noted that risk experts communicating behavioral precautions to those living in minority communities may regard their information as, say, technical discussions of chronic risk exposure, whereas those receiving the risk information may be thinking more fully in terms of distributive justice or the relationship between risk exposure and racial equality. ${ }^{(32)}$ Risk communicators might, alternately and wisely, reframe their messages with reference to justice by explaining, for example, how their actions in site A (a minority community) are similar to those taken in site B (a nonminority community), or how considerations of justice and risk exposure have been addressed in the site in question versus related contexts.

Similarly, Satterfield et al. have argued that in risk remediation contexts, clean up workers who enter minority neighborhoods fully clothed in protective suits or machinery may inadvertently become signals that evoke, among residents, justice- and vulnerability-relevant conclusions. ${ }^{(34)}$ In one contaminated African-American community it was found that: "Visually compelling recollections of heavy machinery and workers in prophylactic suits seemed to say that the residents [there] ought to have been safeguarded these many years ... or, more 
cynically, that the residents were a socially disposable population, unworthy of protection in the first place" (p. 76). The tragic irony in remediation contexts is that remedies for protecting exposed communities may exacerbate the very concerns they ought ideally to alleviate.

In the end, fuller recognition of the fact that subjective and sociopolitical factors (vulnerability and justice included) shape the perception of risk may move us toward policy that is both responsive to and genuinely reflects diverse meanings of risk and diverse experiences of risk management. 


\subsection{NOTES}

' Respondents were also asked to rate a subset of these items in terms of health and safety "risks to you and your family". The pattern of results was similar to those found to the American public.

${ }^{2}$ We recognize that 'race' is (and should be) a contested term in the social sciences as efforts to distinguish biophysical features of racial groups have largely failed. The construct "race" is nonetheless widely meaningful in public life and remains an important social basis through which humans define themselves and are defined by others.

${ }^{3}$ When a Bonferroni test was performed, significant differences were found between nonwhite females and white females on 8 (not 11) items. The Bonferroni test also reduced the number of significant differences between nonwhite males and nonwhite females to 2 from 10 under the Tukey post-hoc test.

${ }^{4}$ The specific demographic and attitudinal variables that distinguish the subset of white males with lower risk perceptions (versus non-low risk white males, white females, and nonwhite males and females) are listed below. The comparisons reported are statistically significant at $p<$ .05 . There were no differences in age distributions across respondent groups. However, white males were more likely to hold college or postgraduate degrees $(46.0 \%$ college or postgraduate degree, versus $26.7 \%$ for all other groups), have higher household incomes (58.3\% above $\$ 45,000$ vs. $33.2 \%$ ), and be politically conservative ( $45.3 \%$ vs. $34.3 \%$ ). They were also more likely to:

- agree that the economic benefits from industries located in their community are greater than the risks $(69.1 \%$ vs. $55.9 \%)$.

- agree that the benefits from science and technology outweigh the risks they create $(69.1 \%$ vs. 


\section{$54.4 \%)$}

- agree that in a fair system, people with more ability should earn more (89.9\% vs. $83.2 \%)$.

- disagree that people in positions of authority tend to abuse their power (30.2\% vs. $18.4 \%)$.

- disagree that what this world needs is a more equal distribution of wealth $(54.0 \%$ vs. $24.3 \%)$.

- disagree that people living near a nuclear power plant should be able to vote and to close the plant if they think it is not being run safely (46.8\% vs. $15.3 \%)$.

- disagree that there are serious environmental health problems where they live $(80.6 \%$ vs. $62.3 \%$ ).

${ }^{5}$ Interestingly, Finucane et al. ${ }^{(27)}$ did find that although white males believed that it was acceptable to impose small risks on society without their knowledge, white males' trust of the institutions that manage risks was qualified, indicating that they preferred (more than others) to control or manage risks themselves.

${ }^{6}$ Some of the items in this set were inspired, in part, by Srole's early 'political alienation' question set. ${ }^{(29)}$

${ }^{7}$ We do not mean to imply that discrimination should be causally explained as feelings of vulnerability and discrimination. We assume, rather, that injustice is structurally rooted but that it may manifest, personally, in these and other feelings.

${ }^{8}$ A comparison of vulnerability and justice index scores for the low-risk white male group (as defined in section 3.1 above) versus the non low-risk white male group is also instructive. The vulnerability and justice mean index scores for low-risk white males are significantly lower than are the mean scores for all other white males as well as all other nonwhite groups. These data are recorded in the following table: 
Means: Low Risk White Males vs. Others

\begin{tabular}{|l|l|l|l|l|}
\hline Variable/Scale & $\begin{array}{l}\text { Low Risk White } \\
\text { Male }(n=157)\end{array}$ & $\begin{array}{l}\text { Non-Low Risk White } \\
\text { Male }(n=169)\end{array}$ & $\begin{array}{l}\text { All Others } \\
(n=533)\end{array}$ & $\begin{array}{l}\text { Tukey Significant } \\
\text { differences }\end{array}$ \\
\hline Vulnerability & 1.84 & 2.08 & 2.13 & $\mathrm{a} \mathrm{b}$ \\
\hline $\begin{array}{l}\text { Environmental } \\
\text { Justice }\end{array}$ & 2.43 & 2.72 & 2.75 & $\mathrm{ab}$ \\
\hline
\end{tabular}

Source: 1997 National Risk Survey (weighted data).

Significant differences identified by Tukey test $(\mathrm{p}<.05)$ :

$\mathrm{a}=$ Low risk white male vs. Non-low risk white male

$\mathrm{b}=$ Low risk white male vs. All Others

${ }^{9}$ The sample sizes here total 222 and are unweighted because we are looking at race and gender effects. The earlier sample size of $n=129$ reflects weighting to adjust oversampled groups back to their respective proportions within the U. S. population as a whole.

${ }^{10}$ Interestingly, Greenberg and Schneider argue that no demonstrable gender differences in risk perceptions are found "among males and females who actually live in stressed neighborhoods with multiple hazards" (Ref. 17, p. 503). Men, they argue, are as likely as women to be personally threatened by hazards that are figuratively and sometimes literally "in their face" ( $p$. 509). They regard their findings as consistent with the "white male effect" in that the difference in their data between men and women in non-stressed neighborhoods may well be an artifact of extremely low levels of concern expressed by a subset of white males. This does not negate the fact, however, that the experience of actually living in a stressed neighborhood may substantively alter one's perception of risk. 


\subsection{REFERENCES}

1. Flynn, J., Slovic, P., \& Mertz, C. K. (1994). Gender, race, and perception of environmental health risks. Risk Analysis, 14(6), 1101-1108.

2. Slovic, P. (1987). Perception of risk. Science, 236, 280-285.

3. Slovic, P. (1999). Trust, emotion, sex, politics, and science: Surveying the riskassessment battlefield. Risk Analysis, 19(4), 689-701.

4. Stern, P. C., Dietz, T., \& Kalof, L. (1993). Value orientations, gender, and environmental concern. Environment and Behavior, 25, 322-348.

5. Bord, R., \& O'Connor, R. E. (1997). The gender gap in environmental attitudes: The case of perceived vulnerability to risk. Social Science Quarterly, 78, 831-840.

6. Davidson, D., \& Freudenburg, W. (1997). Gender and environmental risk concerns: A review and analysis of available research. Environment and Behavior, 28, 302-339.

7. Kalof, L., Dietz, T., Guagnano, G., \& Stern, P. C. (2002). Race, gender and environmentalism: The atypical values and beliefs of white men. Race, Gender \& Class, 9(2), 119.

8. Gutteling, J. M., \& Wiegman, O. (1993). Gender-specific reactions to environmental hazards in the Netherlands. Sex Roles, 28, 433-447.

9. Mohai, P., \& Bryant, B. (1998). Is there a "race" effect on concern for environmental quality? Public Opinion Quarterly, 62, 475-505.

10. Jones, R. E. (1998). Black concern for the environment: Myth versus reality. Society and Natural Resources, 11, 209-228. 
11. Johnson, B. B. (2002). Gender and race in beliefs about outdoor air pollution. Risk Analysis, 22(4), 725-738.

12. Bullard, R. D. (1990). Dumping in Dixie: Race, class and environmental quality. Boulder, CO: Westview.

13. Beck, U. (1992). Risk society: Towards a new modernity. London: Sage.

14. Beck, U. (1999). World risk society. Malden, MA: Polity Press.

15. Graham, J., Beaulieu, N. D., Sussman, D., Sadowitz, M., \& Li, Y. (1999). Who lives near Coke plants and oil refineries? An exploration of the environmental inequity hypothesis. Risk Analysis, 19, 171-186.

16. Zimmerman, R. (1993). Social equity and environmental risk. Risk Analysis, 13, 649666.

17. Greenberg, M., \& Schneider, D. (1995). Gender differences in risk perception: Effects differ in stressed versus non-stressed environments. Risk Analysis, 15, 503-511.

18. Sexton, K., \& Anderson, Y. B. (1993). Equity in environmental health: Research issues and needs [Special issue]. Toxicology and Industrial Health, 9(5).

19. Lester, J., Allen, H., \& Hill, K. (2001). Environmental justice in the United States: Myths and realities. Boulder, CO: Westview.

20. Greenberg, M. (1993). Proving environmental equity in siting locally unwanted land uses. Risk: Issues in Health and Safety, 235, 235-252.

21. Szasz, A. (1994). Ecopopulism: Toxic waste and the movement for environmental justice (Vol. 1). Minneapolis: University of Minnesota Press. 
22. Taylor, D. (2000). The risk of the environmental justice paradigm. American

Behavioral Scientist, 43, 508-580.

23. Watts, M., \& Bohle, H. (1993). The space of vulnerability: The causal structure of hunger and famine. Progress in Human Geography, 17(1), 43-67.

24. Kraus, N., Malmfors, T., \& Slovic, P. (1992). Intuitive toxicology: Expert and lay judgments of chemical risks. Risk Analysis, 12, 215-232.

25. Slovic, P. (1992). Perception of risk: Reflections on the psychometric paradigm. In S. Krimsky \& D. Golding (Eds.), Social theories of risk (pp. 117-152). New York: Praeger.

26. Slovic, P., Fischhoff, B., \& Lichtenstein, S. (1979). Rating the risks. Environment, $21(3), 14-20,36-39$

27. Finucane, M. L., Slovic, P., Mertz, C. K., Flynn, J., \& Satterfield, T. A. (2000). Gender, race, and perceived risk: The "white male" effect. Health, Risk, \& Society, 2(2), 159172.

28. Jones, E. E., Farina, A., Hastorf, A. H., Markus, H., Miller, D. T., Scott, R. A., \& French, R. d. (1984). Social stigma: The psychology of marked relationships. New York: W. H. Freeman.

29. Srole, L. (1965). Social integration and certain corollaries. American Sociological Review, 21(6), 709ff.

30. DeVellis, R. F. (1991). Scale development: Theory and applications. Newbury Park, CA: Sage. 
31. Bellinger, D., Levington, A., \& Waternaux, C. (1987). Longitudinal analyses of prenatal and postnatal lead exposure and early cognitive development. New England Journal of Medicine, 322, 83-88.

32. Agency for Toxic Substances and Disease Registry. (1995, September 1). Case studies in environmental medicine: Lead toxicity. Retrieved June 17, 2002, from the World Wide Web: http://www.atsdr.cdc.gov/HEC/HSPH/caselead.html

33. Needleman, H. L., Schell, A., \& Bellinger, D. (1990). The long-term effects of exposure to low doses of lead in childhood: 11-year follow-up report. New England Journal of Medicine, 322, 83-88.

34. Satterfield, T. A., Slovic, P., Gregory, R., Flynn, J., \& Mertz, C. K. (2001). Risk lived, stigma experienced. In J. Flynn \& P. Slovic \& H. Kunreuther (Eds.), Risk, media, and stigma: Understanding public challenges to modern science and technology (pp. 69-83). London: Earthscan.

35. Vaughn, E. (1995). The significance of socioeconomic and ethnic diversity for the risk communication process. Risk Analysis, 15, 169-180.

36. Capek, S. M. (1993). The "environmental justice" frame: A conceptual discussion and an application. Social Problems, 40, 5-24.

37. Gustafson, P. E. (1998). Gender differences in risk perception: Theoretical and methodological perspectives. Risk Analysis, 18(6), 805-811. 
Table I. Distributions for Items Comprising the Vulnerability Index

\begin{tabular}{|c|c|c|c|c|}
\hline Item & $\begin{array}{l}\text { White } \\
\text { Males }\end{array}$ & $\begin{array}{c}\text { White } \\
\text { Females } \\
\end{array}$ & $\begin{array}{c}\text { Nonwhite } \\
\text { Males }\end{array}$ & $\begin{array}{c}\text { Nonwhite } \\
\text { Females } \\
\end{array}$ \\
\hline I often feel discriminated against. ${ }^{a}$ & $\%$ & $\%$ & $\%$ & $\%$ \\
\hline Strongly agree/Agree & 18.0 & 20.9 & 49.4 & 50.6 \\
\hline Strongly disagree/Disagree & 81.3 & 78.3 & 49.8 & 48.0 \\
\hline \multicolumn{5}{|l|}{ My whole world feels like it is falling apart. ${ }^{a}$} \\
\hline Strongly agree/Agree & 7.3 & 12.3 & 23.3 & 21.8 \\
\hline Strongly disagree/Disagree & 92.4 & 87.5 & 75.5 & 77.8 \\
\hline \multicolumn{5}{|l|}{$\begin{array}{l}\text { People like me aren't benefiting in the growth of } \\
\text { the economy. }\end{array}$} \\
\hline Strongly agree/Agree & 29.4 & 41.3 & 43.7 & 54.6 \\
\hline Strongly disagree/Disagree & 69.2 & 56.7 & 53.9 & 43.3 \\
\hline \multicolumn{5}{|l|}{ I have very little control over risks to my health. ${ }^{a}$} \\
\hline Strongly agree/Agree & 16.3 & 19.1 & 31.4 & 29.5 \\
\hline Strongly disagree/Disagree & 83.4 & 80.7 & 67.4 & 69.5 \\
\hline \multicolumn{5}{|l|}{$\begin{array}{l}\text { Would you rate your personal health as excellent, } \\
\text { good, fair or poor? }\end{array}$} \\
\hline Excellent/good & 82.7 & 84.6 & 76.7 & 76.0 \\
\hline Fair/poor & 17.0 & 15.4 & 23.3 & 24.0 \\
\hline \multicolumn{5}{|l|}{$\begin{array}{l}\text { How would you rate the quality of medical care } \\
\text { that is available to you and your family? }\end{array}$} \\
\hline Excellent/good & 81.3 & 78.6 & 66.9 & 66.2 \\
\hline Fair/poor & 18.7 & 20.6 & 32.7 & 33.8 \\
\hline Social vulnerability index mean ${ }^{c}$ & 1.96 & 2.05 & 2.24 & 2.30 \\
\hline$N$ & 289 & 383 & 245 & 275 \\
\hline
\end{tabular}

Note. Percentages might not add to $100 \%$ as DK and NA are not shown. Source: 1997 National Risk Survey.

${ }^{a}$ Significant at $p<.0001$ by chi-square test

${ }^{\mathrm{b}}$ Significant at $p<.01$ by chi-square test

${ }^{c}$ Social Vulnerability Index: significance differences: white males with all other groups, white females with all other groups (Tukey, $\mathrm{p}<.05$ ). 
Table II. Distributions for Items Comprising the Environmental Justice Index

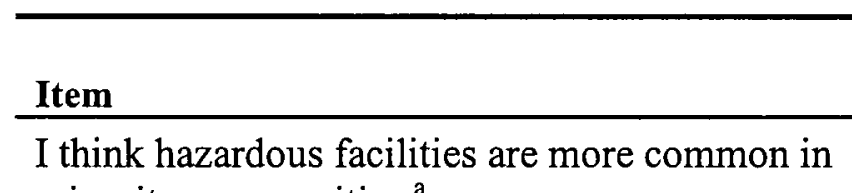
minority communities. ${ }^{a}$

$$
\begin{array}{r}
\text { Strongly agree/Agree } \\
\text { Strongly disagree/Disagree }
\end{array}
$$

White

Males

$\begin{array}{ccc}\text { White } & \begin{array}{c}\text { Nonwhite } \\ \text { Males }\end{array} & \begin{array}{c}\text { Nonwhite } \\ \text { Females }\end{array} \\ \text { Females } & \text { Femal }\end{array}$

$\%$

50.5

43.6

$\%$

47.0

46.0
$\%$
66.5

$\%$

29.8

71.6

24.7

For economic reasons, minority communities are forced to accept more industrial pollution than non-minority communities. ${ }^{a}$

$\begin{array}{rrrrr}\text { Strongly agree/Agree } & 54.0 & 57.2 & 76.3 & 76.4 \\ \text { Strongly disagree/Disagree } & 41.2 & 37.9 & 21.6 & 20.0\end{array}$

Minority communities lack the political clout to stop hazardous facilities from being located near them. ${ }^{a}$

$\begin{array}{rrrrr}\text { Strongly agree/Agree } & 56.4 & 56.1 & 76.3 & 75.3 \\ \text { Strongly disagree/Disagree } & 42.2 & 39.7 & 22.0 & 21.8\end{array}$

The government should restrict the placing of hazardous facilities in minority communities. ${ }^{\text {a }}$

$\begin{array}{rrrrr}\text { Strongly agree/Agree } & 63.7 & 71.8 & 80.8 & 90.9 \\ \text { Strongly disagree/Disagree } & 30.5 & 21.2 & 17.6 & 8.0\end{array}$

\begin{tabular}{rrrrr} 
Environmental justice index mean $^{\mathrm{b}}$ & 2.58 & 2.64 & 2.88 & 2.96 \\
$N$ & 289 & 383 & 245 & 275 \\
\hline
\end{tabular}

Note. Percentages might not add to $100 \%$ as DK and NA are not shown. Source: 1997 National Risk Survey.

${ }^{a}$ Significant at $p<.0001$ by chi-square test.

${ }^{\mathrm{b}}$ Environmental Justice Index significance differences: white males with nonwhite males and nonwhite females, white females with nonwhite males and nonwhite females (Tukey, $\mathrm{p}<.05$ ). 
Table III. Two Regression Models Predicting Risk Perception Index

\section{Model 1}

Independent Variables

Standardized Coefficients

Gender
Race
$F$ value
$p>F$
R-square

0.28

$-0.22 * *$

87.03

0.0001

0.1277

\section{Model 2}

Independent Variables

Standardized Coefficients

Increment in

Independent Variables

First 2 variables forced in first

$\begin{array}{rccc}\text { Vulnerability } & 0.27^{* * * *} & & \\ \text { Environmental Justice } & 0.18^{* * * *} & 0.1668 & \\ \text { Gender } & 0.24^{* * * *} & 0.2249 & 0.0581 \\ \text { Race } & -0.10^{* * *} & 0.2346 & 0.0097 \\ F \text { value (full model) } & 90.33 & & \\ p>F & 0.0001 & & \end{array}$

Coding:

Gender: $0=$ men $1=$ women

Race: $0=$ nonwhite $1=$ white

Source: 1997 National Risk Survey

$* * * p<.001$
$* * * * p<.0001$ 
Table IV. Regression Model Predicting Risk Perception Index from Other Sociodemographic Variables

\section{Model 3}

Independent Variables

First 2 variables forced in first

$\begin{array}{rccc}\text { Vulnerability } & 0.20 * * * * & \\ \text { Environmental Justice } & 0.19 * * * * & 0.1615 & \\ \text { Gender } & 0.22 * * * * & 0.2199 & 0.0584 \\ \text { Education } & -0.18^{* * * *} & 0.2464 & 0.0265 \\ \text { Race } & -0.09 * * & 0.2547 & 0.0083 \\ \text { Church Attendance } & 0.08 * * & 0.2604 & 0.0057 \\ \text { Political orientation } & -0.05 & 0.2622 & 0.0018 \\ \text { Age } & 0.02 & 0.2627 & 0.0005 \\ \text { Income } & -0.01 & 0.2627 & 0.0001 \\ & & & \\ F \text { value (full model) } & 41.54 & & \\ p>F & 0.0001 & & \end{array}$

Standardized

Coefficients

R-squared
Increment in

R-squared 
Figure Captions

Figure 1. Perceived risks to American public: Means by race and gender - white vs. nonwhite

Figure 2. Risk-perception means by response to "I often feel discriminated against"

Figure 3. Risk-perception means by response to "The government should restrict the placing of hazardous facilities in minority communities"

Figure 4. Risk-perception means by respondents in the highest third and lowest third of scores on the vulnerability and environmental justice indices

Figure 5. Risk-perception means by vulnerability and environmental justice by race and gender: High on both 
Figure 1. Perceived risks to American public: Means by race and gender - White vs. Nonwhite

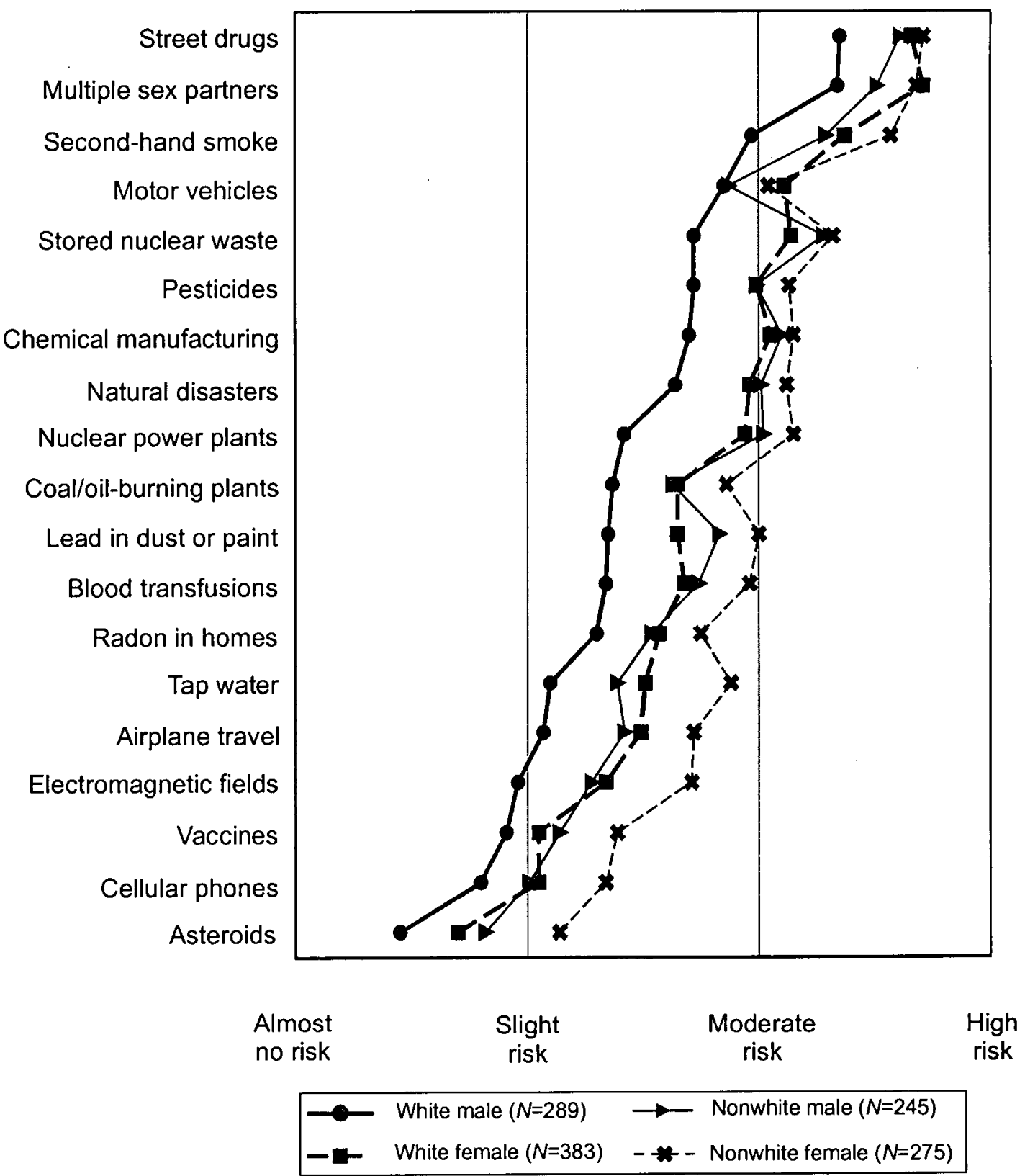

Nonwhite includes Hispanic, African American, Asian, Native American, and multiracial groups. Source: 1997 National Risk Survey. 
Vulnerability and Risk

Page 37

Figure 2. Risk-perception means by response to "I often feel discriminated against"

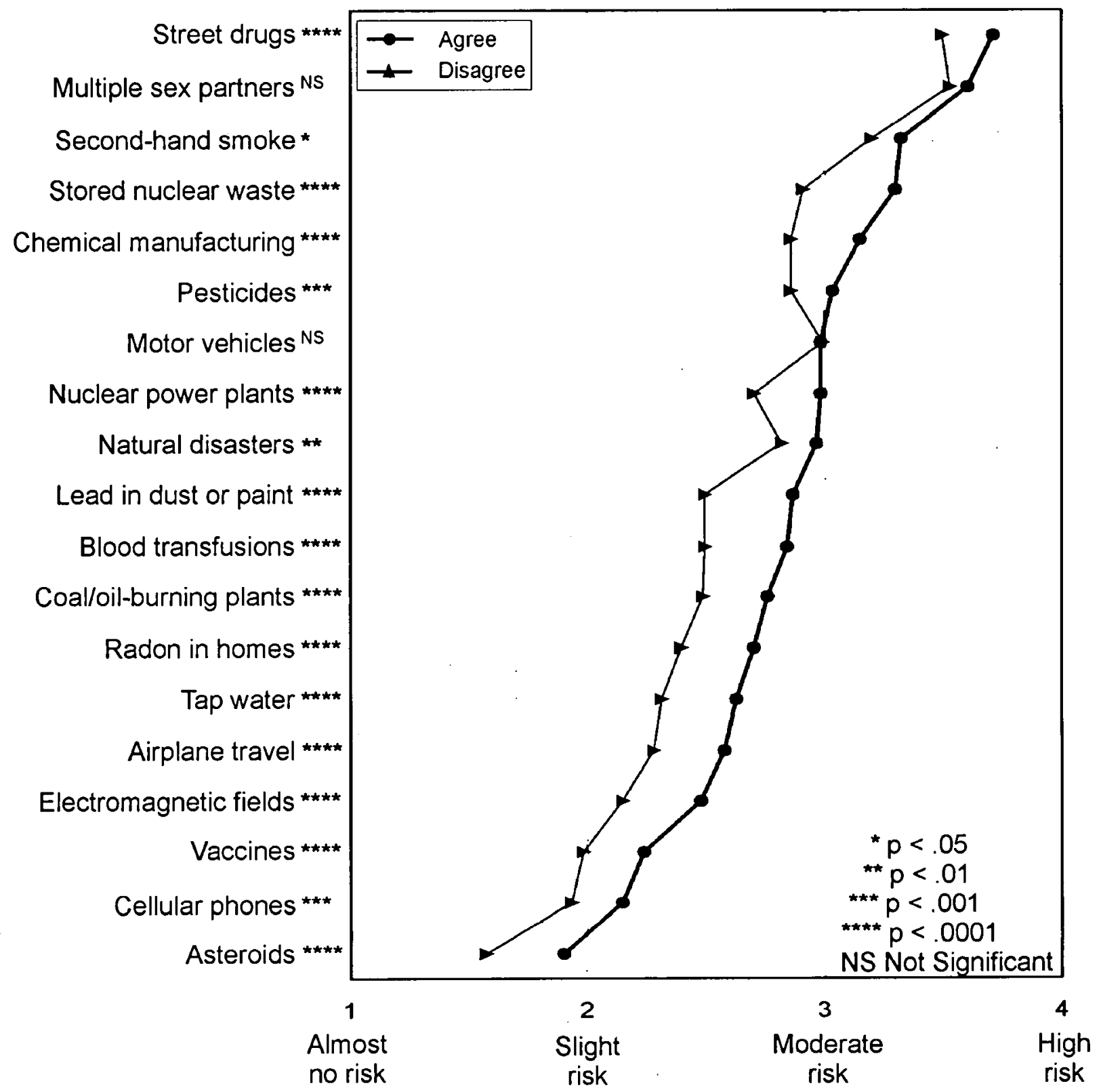

Source: 1997 National Risk Survey: U.S. population as a whole. 


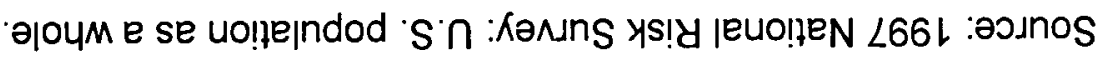

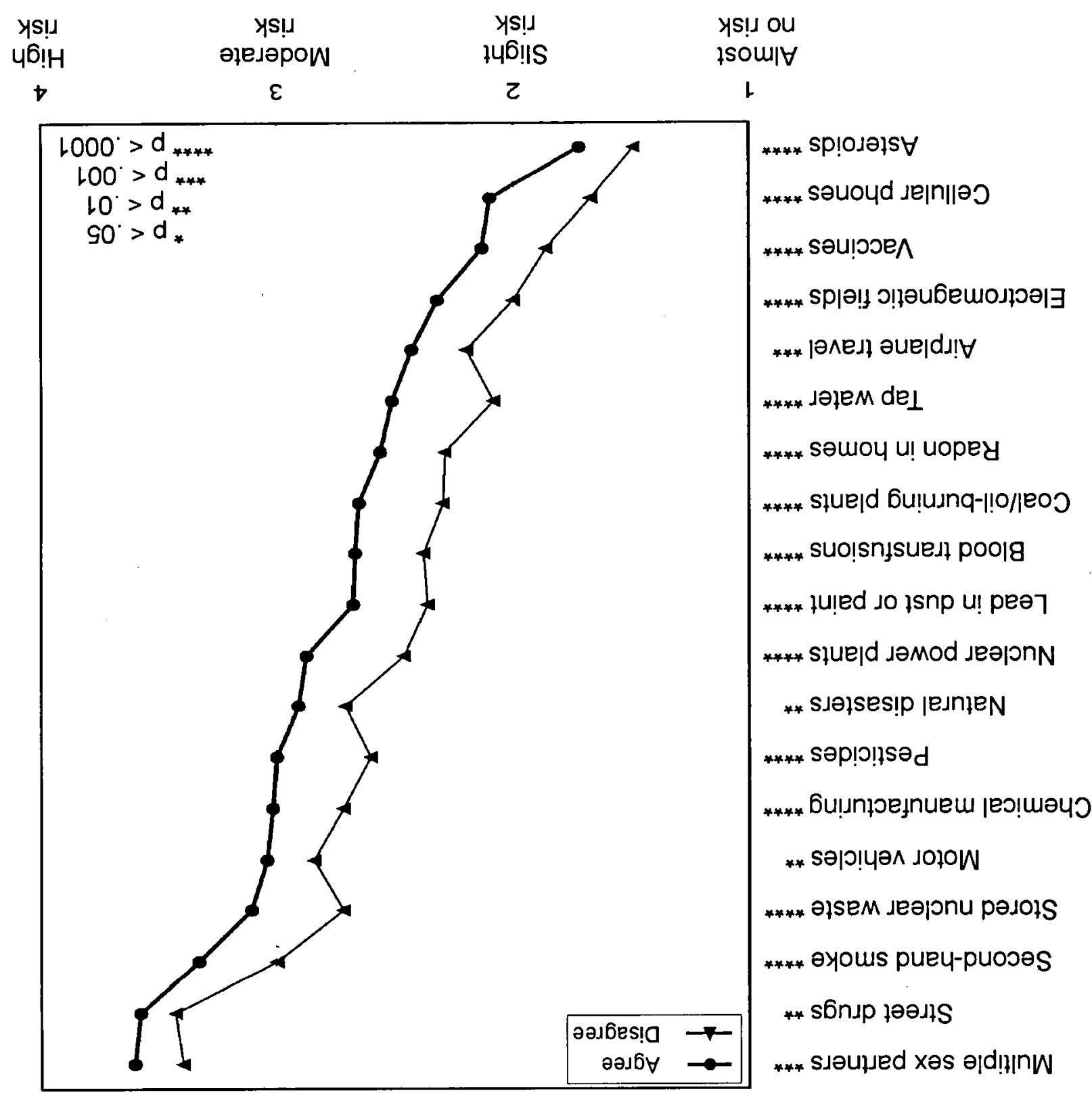

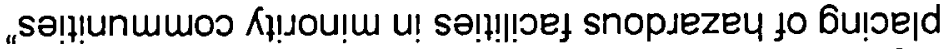

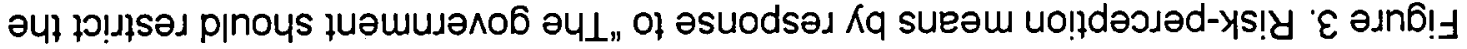


Vulnerability and Risk

Page 39

Figure 4. Risk-perception means by respondents in the highest third and lowest third of scores on both the vulnerability and environmental justice indices

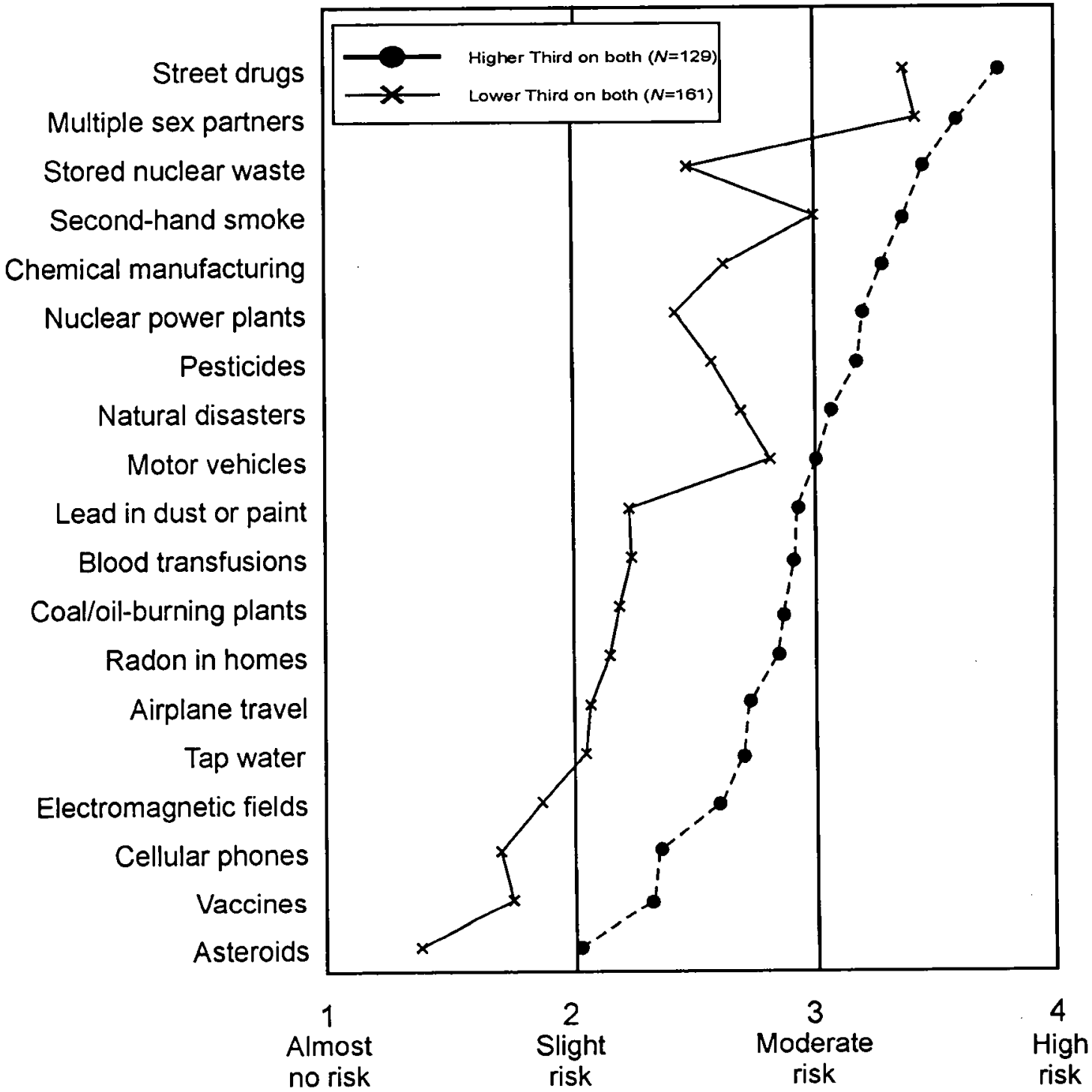

Source: 1997 National Risk Survey: U.S. Population as a whole 
Figure 5. Risk-perception means by vulnerability and environmental justice by race and gender: High on both

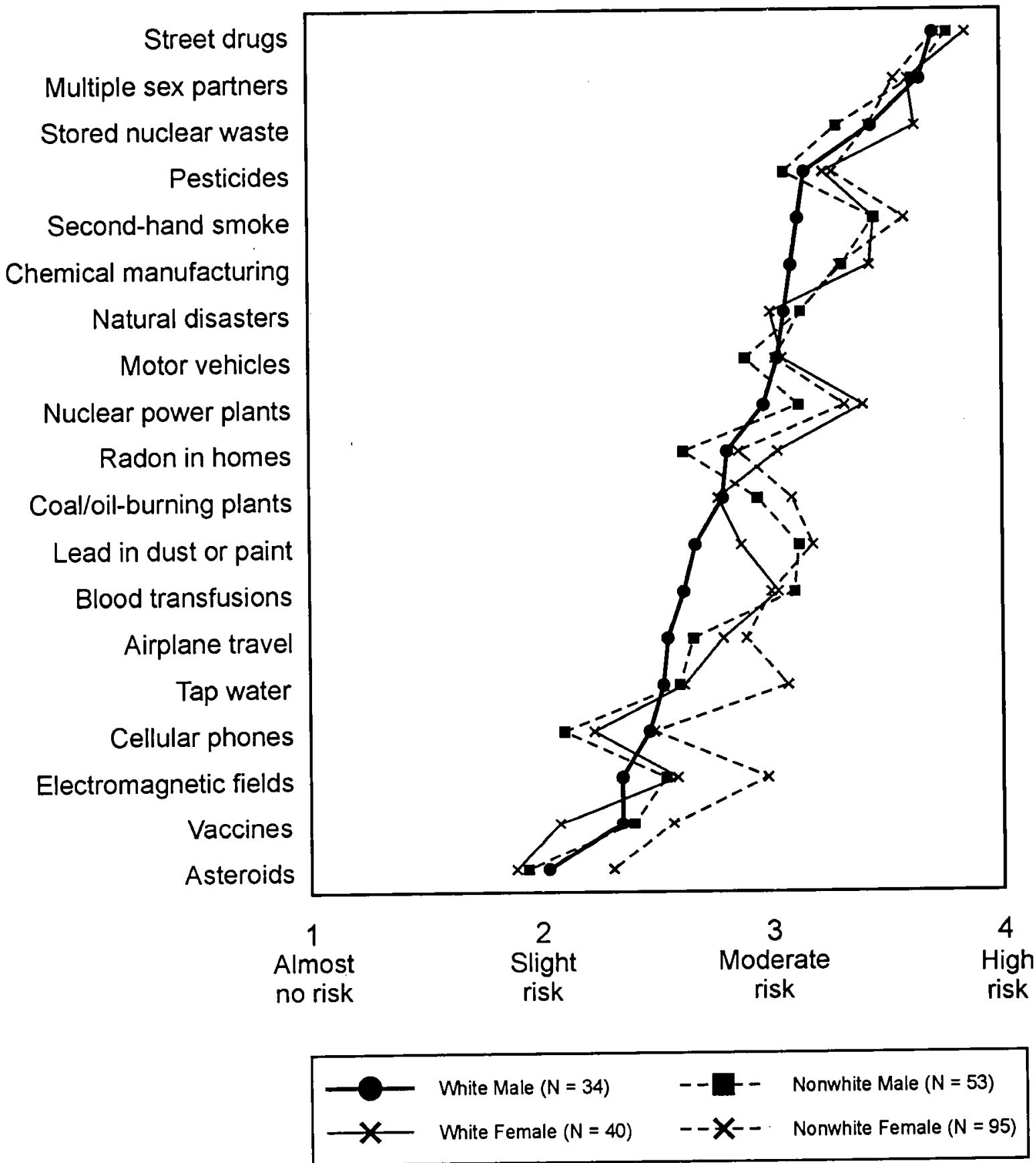

Source: 1997 National Risk Survey 